\title{
Influence of Real Ear Resonance on Male Voice Formant Frequency
}

\author{
Seung-Deok Heo ${ }^{\mathrm{a}}$, Hui-Ra Kang ${ }^{\mathrm{b}}$, Do-Heung Ko ${ }^{\mathrm{c}}$ \\ ${ }^{a}$ Department of Speech-Language Pathology, College of Rehabilitation Science, Daegu University, Gyeongsan, Korea \\ ${ }^{b}$ Department of Rehabilitation Science, Graduate School of Daegu University, Gyeongsan, Korea \\ 'Division of Audiology Speech-Language Pathology, Hallym University, Chuncheon, Korea
}

\author{
Correspondence: Seung-Deok Heo, PhD \\ Department of Speech-Language Pathology, \\ College of Rehabilitation Science, Daegu \\ University, 201 Daegudae-ro, Jillyang-eup, \\ Gyeongsan 38453, Korea \\ Tel: $+82-53-850-4326$ \\ Fax: +82-53-850-4329 \\ E-mail: audiolog@daegu.ac.kr
}

Received: April 4, 2017

Revised: June 7, 2017

Accepted: June 23, 2017

This work was supported by research funds from Daegu University, 2016.

\begin{abstract}
Objectives: Voice in the external auditory canal (EAC) is expected to change while being affected by the resonance of the concha cavity and the EAC. Acoustical analysis should include the frequency range of EAC resonance. This study aims to determine the influence of the resonance of the EAC by analyzing formant. Methods: Male voiced monophthongs were used in this study; the most frequently used vowels were /a/, /i/, /u/, /e/, /o/. Experimental voice in the real ear and sound field was recorded by 12 healthy young female subjects. Voice characteristics were analyzed by Praat (ver. 6.0.19). The formant frequency of the sample and experimental voice were analyzed with descriptive statistics. The relationship between the sample voice and experimental voice was analyzed by a paired $t$-test. Results: The voices between the sound field and real ear demonstrated significant differences at $\mathrm{F} 3$ and $\mathrm{F} 4$ of /a/, F2, F3, and F4 of /i/, all formant frequencies of /u/, F2 and F4 of /e/, and F1, F3, and F4 of /o/ $(p<.05)$. Conclusion: Voice in the real ear is collected under the influence of resonances, distance from the sound source, and rounding. Understanding these changes is expected to improve the analysis of timbre and individual voices and speech understanding.
\end{abstract}

Keywords: Formant, Resonance, External auditory canal
공명관을 통과한 소리는 기본음과 배음 또는 화음 등으로 그 특 성을 표현할 수 있다. 배음의 크기는 간섭이 일어나지 않으면 시간 과 거리에 따라 일정하게 작아진다. 그러나 공명이나 간섭 등에 영 향을 받으면 진폭이 일정하게 커졌다가 작아지고, 다시 커졌다가 작 아지기를 반복한다(Martin \& Clark, 2015). 이러한 일련의 변화에 서 진폭이 높은 정점(peak)을 '포먼트 주파수(formant frequency)' 라 하며, 만들어진 순서에 따라 F1, F2, F3, ..., Fn 등으로 표현한다 (Borden, Harris, \& Raphael, 1994; Denes \& Pinson, 1995; Ferrand, 2007; Johnson, 2003). 포먼트 주파수는 성문 스펙트럼, 성도 모양 및 크기, 입술 밖으로 전파되는 양상에 따라 달라진다. 말소리에서 는 F1, F2, F3이 중요하지만(Ferrand, 2007), 모음의 특성은 F1, F2 로 설명한다.

F1은 혀의 높낮이로 결정된다(Borden et al., 1994; Chung et al., 2010; Denes \& Pinson, 1995; Ferrand, 2007; Kim, Kim, Kim, \& Jang,
2013). 고모음 / / 나 원순모음 / 기///기/의 경우 구강이 좁혀지면서 $\mathrm{F} 1$ 이 낮아지고, 저모음/가는 인강이 좁혀져서 F1이 높아진다. F2는 혀의 앞뒤 위치로 결정된다(Borden et al., 1994; Chung et al., 2010; Denes \& Pinson, 1995; Ferrand, 2007; Kim et al., 2013). 후설 또는 원순모음의 경우 연구개 근처가 좁아져서 F2가 낮아지고, 전설 또는 평순모음의 경우 경구개 근처가 좁아져서 F2가 높아진다.

이외에도 F3은 성문, 연구개, 치조 등이 좁아질수록 그리고 성도 길이가 길어질수록 높아지고, 반대로 입술, 경구개, 인두 위쪽 등이 좁아질수록 낮아진다. F3은 음소의 음질을 결정하고, 비언어적 자 극인 시각 자질에 의해서도 언어적 이해와 음운 자질의 발성 과정 에 기여한다(Kim et al., 2013; Parise \& Pavani, 2011). F4는 말소리 의 음질 결정에 관여한다.

소리는 매질을 달리하면서 청각기관 상부로 진행한다. 외이는 청 각기관 입구이면서 청각기관에서 공기를 매질로 소리를 전달하는 
마지막 단계이다. 이러한 외이는 두개골에 함몰되어 있으며, 한 쪽 이 고막으로 닫혀 있는 공명관이어서 공명 이득이 생긴다(Choi, Lee, Choi, \& Heo, 2009; Heo, Lee, Jeon, \& Kim, 2010; Heo, 2012). 공명 주파수 범위는 외이도에서 $2,700 \mathrm{~Hz}$ 범위, 이개강에서 $4,000-$ $5,000 \mathrm{~Hz}$ 이며, 공명 이득은 $10-15 \mathrm{~dB}$ 정도이다(Heo et al., 2010; $\mathrm{Heo}, 2012)$. 외이 공명은 귀꽂이 사용(Kim \& Heo, 2016) 등에 의해 달라질 수 있다. 포먼트 주파수는 정상 또는 병리적 음성을 입술 바 로 앞에서 녹음하여 F1과 F2만을 분석하는 경우가 대부분이며, F3, F4를 포함한 경우는 흔하지 않다(Kim et al., 2013). F3, F4를 포 함하지 않는 것은 고주파수에서 음성에너지 손실이 많아 분석에 어려움이 있고, 음성학적 연구의 외인성 중복(extrinsic redundancy)을 피하기 위한 것이다. 그러나 F3, F4는 외이 공명 주파수 대역 과 겹쳐서 어느 정도 영향을 주게 된다(Heo, Yoo, Jung, \& Lee, 2016; Heo \& Kang, 2017). 따라서 청각학적 측면에서 실험음성학 연구는 $\mathrm{F} 3, \mathrm{~F} 4$ 를 포함할 필요가 있다.

이 연구는 남성 화자가 발성한 단모음을 연구 참여자의 외이도에 서 녹음하여 외이 공명이 포먼트 F1, F2, F3, F4에 미치는 영향을 확 인하고자한다.

\section{연구방법}

\section{연구대상}

대상자들은 연구 목적과 방법을 잘 이해하고, 결과의 연구 목적 활용에 동의하였다.

음성은 청력손실이 없고, 조음 및 음성장애가 없는 24세 남자가 발성하여 녹음하였고(표본 음성), 표본 음성은 외이와 중이가 건강 하고 청력손실이 없는 22 세부터 30 세 사이 $(26 \pm 4)$ 의 여자 12 명에 게 재생하여 이개 상부와 외이도 내부에서 각각 녹음하였다(실험 음성). 참여자의 중이 상태는 이미턴스 청력검사기(GSI 33, GrasonStadler Inc., Eden Prairie, MN, USA)를 이용하여 고막운동도(tympanogram)로 확인하였다. 이들의 고막운동도는 외이도 용적, 정적 탄성, 중이강 압력이 모두 정상 범위에 있는 'A'형이었다.

\section{연구방법}

\section{표본 음성}

표본 음성은 우리말 모음에서 사용빈도가 높고, 꼭지 모음(corner vowel)인 평순중설저모음 / / / 평순전설고모음 / / , 원순후설 고모음/T/를 포함하여, 평순전설중모음/林/, 원순후설중모음/기/ 의 5 개를 사용하였다.

발성 중에는 남성의 음성을 Computerized Speech Lab (CSL-

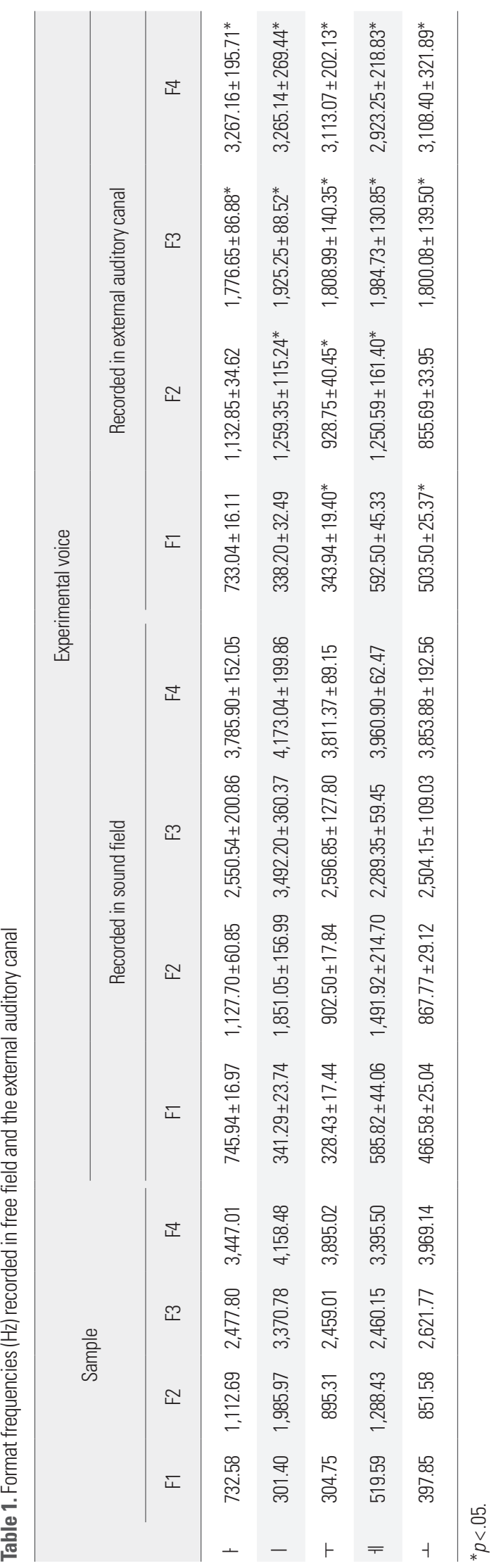


4500, Kaypentax, Montvale, NJ, USA), Multi-Dimensional Voice Program (MDVP-5105 v3.3.0)의 음량지시계(volume unit meter)로 계속감시하였다. 발성은 단음절 낱말을 5 초 동안 일정하게 지속하는 연습을 충분히 하였다. 마이크(SM 48, Shure Inc., Niles, IL, USA) 는 입술 전방 $20 \mathrm{~cm}$ 이내에 두었으며, 녹음은 표본 추출율 44,100 $\mathrm{Hz}$, 양자화 $16 \mathrm{bit}$ 로 하여 개인용 컴퓨터(DBP400-PC313S, 삼성전 자, 한국)에 저장하였다(표본 음성). 표본 음성은 Praat (ver. 6.0.19, University of Amsterdam, Netherlands)으로 분석하였다.

표본 음성의 포먼트 주파수는 F1, F2, F3, F4의 순서로 / 기가 732, $1,112,2,477,3,447 \mathrm{~Hz}$, / / 는 301, 1,985, 3,370, 4,158 Hz, / T/가 304, $895,2,459,3,895 \mathrm{~Hz}$, / 게 / 가 $519,1,288,2,460,3,395 \mathrm{~Hz}$, / 고는 397 , $851,2,621,3,969 \mathrm{~Hz}$ 로 각각 관찰되었다(Table 1).

\section{실험 음성}

실험 음성은 대상자 $315^{\circ}$ 방향(왼쪽 $45^{\circ}$ ) $50 \mathrm{~cm}$ 거리에 둔 스피커 (BR-2280 Stick, Britz, Paju, Korea)에서 75 dB SPL로 출력한 표본 음성을 외이도 내부와 이개 상부 각각에서 동시에 녹음하였다. 출 력음압은 음압계(Ling WAVES SPL meter, WEVOSYS, Baunach, Germany)로 감시하였다.

음장음성 녹음용마이크는이개상부두개골과이개가절흔(notch) 을 이루는 부분에 장착하였다. 외이도 내부 음성 녹음용 마이크에 는 직경 $0.6 \mathrm{~mm}$, 길이 $75 \mathrm{~mm}$ 의 탐침관(probe tube)을 추가로 장착 하였다. 탐침의 끝은 외이도 내부 고막 $1 \mathrm{~cm}$ 가까이까지 삽입하였 다. 마이크는 고성능의 콘덴서 마이크를 자체 제작하였고, 참여자

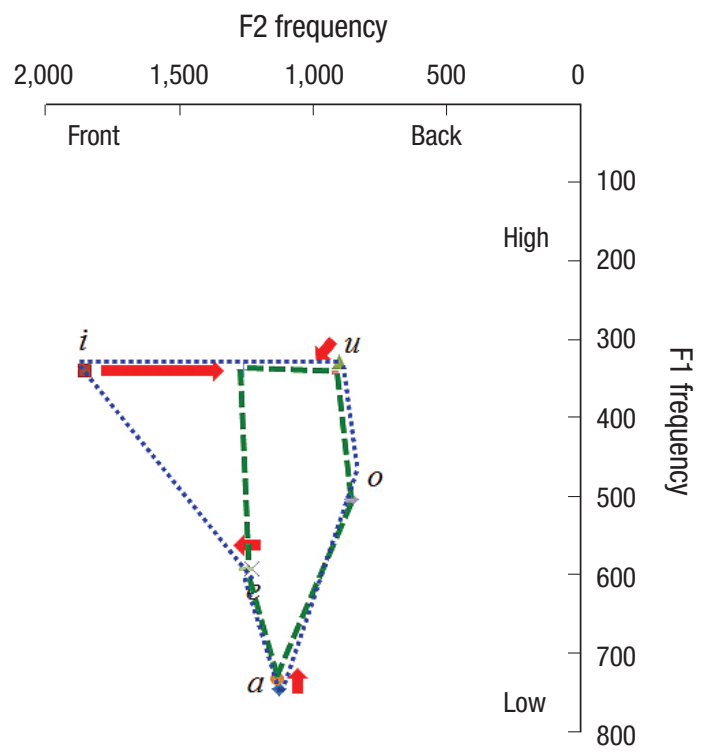

의 머리카락은 단정하게 묶었다.

외이도 내부 음성은 탐침관의 영향을 받기 때문에 이를 보정할 필요가 있으며, 이를 위해 음성을 녹음하기 전 $100 \mathrm{~Hz}$ 부터 6,000 $\mathrm{Hz}$ 까지 $100 \mathrm{~Hz}$ 단위의 순음을 두 개의 마이크로 동시에 녹음하였 다. 실험 음성의 녹음은 2채널 증폭기(Scarlett 6i6, Focusrite, Bucks, $\mathrm{UK}$ )로 증폭한 후, Adobe Audition CS6로 44,100 Hz, 양자화 $16 \mathrm{bit}$ 로 녹음하였고 개인용 컴퓨터(DBP400-PC313S, Samsung, Suwon, Korea)에 저장하였다. 외이도에서 녹음한실험 음성은MatLab(R2014a, MathWorks, Natick, MA, USA)을 이용하여 탐침관에 의한 영향을 보정(calibration)하였다.

\section{음성 분석 및 통계적 검증}

음성 분석에는 청각음성학 전공 교수와 경험이 풍부한 석사과 정 대학원생이 참여하였다. 분석 구간은 실험 음성의 파형을 육안 으로 관찰하여 가장 안정된 범위를 찾고, 이 범위에서 0.1 초 구간을 선택하였다. 포먼트 주파수는 0.1 초 구간에서 구한 최대 18 개 지점 평균으로 하였다. 포먼트 주파수 분석은 Praat (ver. 6.0.19)을 이용 하였고, window length 0.025, dynamic range $38 \mathrm{~dB}$ 로 최대 7,000 $\mathrm{Hz}$ 범위에서 $\mathrm{F} 1, \mathrm{~F} 2, \mathrm{~F} 3, \mathrm{~F} 4$ 를 분석하였다. 그러나 외이도 음성 녹 음용 탐침 보정 주파수 한계를 고려하면 주파수 범위는 $6,000 \mathrm{~Hz}$ 까지로 볼 수 있고, 실지로 주파수가 가장 높은 F4는 $5,000 \mathrm{~Hz}$ 를 초 과하지 않았다.

포험트 주파수 F1, F2, F3, F4는 기술통계 하였고, 이개 위쪽과 외 이도 안쪽에서 구한 실험 음성 사이의 포먼트 주파수 사이의 차이

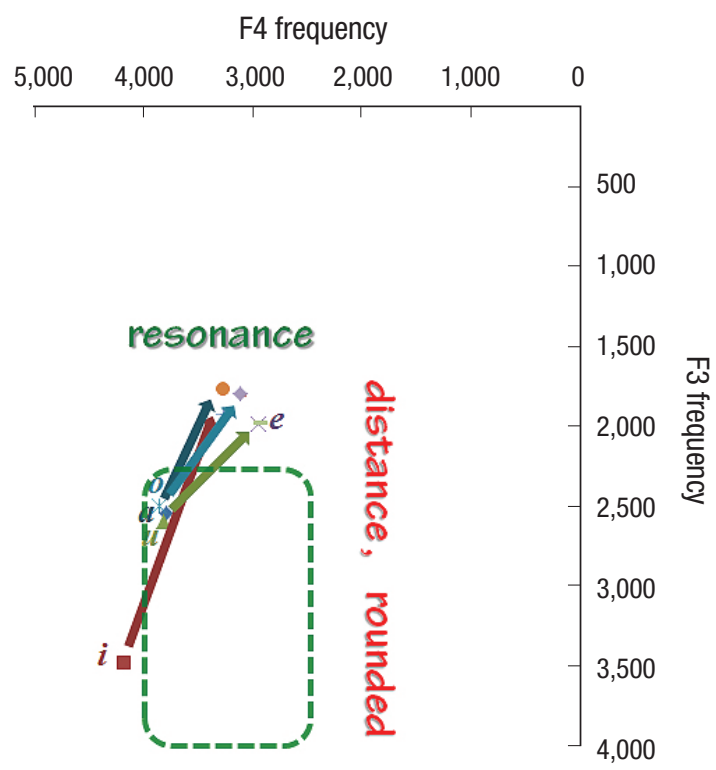

Figure 1. Change of formant frequencies from F1 to F1 in real ear. 
는 대응표본 $t$-test (SPSS 22.0)와 Wilcoxon test (///의 F2와 /T/, /_시의 F3)로 검증하였다.

\section{연구결과}

이개 상부에서 녹음한 음성의 포먼트는 F1, F2, F3, F4의 순서로 /가가 $745,1,127,2,550,3,785 \mathrm{~Hz}$, / / 가 $341,1,851,3,492,4,173 \mathrm{~Hz}$, / T/가 $328,902,2,596,3,811 \mathrm{~Hz}$, / 게/가 $585,1,491,2,289,3,960 \mathrm{~Hz}$, /고/가 $466,867,2,504,3,853 \mathrm{~Hz}$ 로 각각 관찰되었다(Table 1, Figure 1).

실이에서 녹음한 음성의 포먼트는 같은 순서로 / / / 가 733, 1,132, $1,776,3,267 \mathrm{~Hz}$, / / 가 338, 1,259, 1,925, 3,265 Hz, / T/가 343, 928, $1,808,3,113 \mathrm{~Hz}$, / 게/가 $592,1,250,1,984,2,923 \mathrm{~Hz}$, /ㄱ/가 503,855 , $1,800,3,108 \mathrm{~Hz}$ 로 각각 관찰되었다(Table 1, Figure 1).

두 음성의 포먼트 변화는 / / / 에서 F3, F4가 유의하게 낮아졌고 $(p=.000), / / /$ 에서 F2, F3, F4가 유의하게 낮아졌다 $(p=.000)$. /T/ 에서는 F1 $(p=.036)$ 과 F2 ( $p=.040)$ 가 유의하게 높아졌고, F3과 F4 가 유의하게 낮아졌다 $(p=.000)$. / 게/에서는 F2 ( $p=.008)$, F3과 F4 $(p=.000)$ 가 유의하게 낮아졌다. / 노/에서는 F1이 유의하게 높아졌 고 $(p=.004), \mathrm{F} 3$ 과 $\mathrm{F} 4$ 가 유의하게 낮아졌다 $(p=.000)$.

$\mathrm{F} 1$ 은 후설모음/T/와/ㄱ//ㅏㅏ 높아졌다. F2는 후설모음/T/가 높 아졌고, 전설 고모음 / / 및 중모음 / 게/가 낮아졌다 $(p<.05)$. F3과 $\mathrm{F} 4$ 는 모든 모음에서 유의하게 낮아졌다 $(p<.05)$.

\section{논의 및 결론}

포먼트 주파수는 성도 영향을 받은 배음 성분의 스펙트럼에 의 해 결정되는데(Kent \& Read, 2003), F1과 F2는 대화나 자연 및 구분 발화, 낭독등음성 산출 방법, 단일 또는 이중 언어 환경(Kim \&Yoon, 2015; Kwon, Ko, Kim, Lee, \& Jeong, 2007; Yang, 2014) 등에 의해서 도 달라진다. $\mathrm{F} 1$ 의 표준편차는 발화자 감정 개입에 의해 100 부터 $300 \mathrm{~Hz}$ 정도로 커질 수 있다(Yi, 2011). 그러나 이 연구에서 사용한 표본 음성은 한 명의 화자가 구분 발화하였고, 실험 음성의 표준편 차도 $45 \mathrm{~Hz}$ 를 넘지 않아서 이러한 영향들을 배제할 수 있다.

실이에서 녹음한 모음///,///,/T/,//n/,/ㄱ/의 F3, F4는 음장과 비교하여 유의하게 낮아졌다. 이 변화는 이들 포먼트 주파수 범위 가 외이 공명 주파수 범위와 겹쳐지고, $15 \mathrm{~dB}$ 정도에 이르는 공명 이득이작용한 것으로 보인다.

발성 습관은 여자들의 경우 분명하게 말하려는 의도로 성도를 크게 움직이지만 남자들의 경우 혀를 구강 아래에 그대로 두고 움
직임이 적다. 통계적으로 유의하지 않았지만 / / / 의 F1이 낮아지고 $\mathrm{F} 2$ 가 높아진 것은 입 밖으로 나온 후, 외이도로 진입하는 과정에서 도간섭받지 않은 것으로 볼 수 있다.

전설 고모음인 ///는 혀가 구개 가까이 위쪽으로, 경구개 가까이 앞쪽으로 마찰이 일어나지 않을 정도로 접근한 상태에서 조음된 다. 실이 음성 F2가 낮아진 것은 이러한 조음 방법과 관련이 있을 것으로 추정된다.

후설 고모음/T//는 혀가 뒷부분을 위쪽으로 하여 연구개에 접 근된 상태로, 조음기관이 닫혀 진 것과 같은 모양으로 조음된다. 실 이 음성 / T/는 좁혀진 인두강 공간을 통과한 후, 음장에 의해 구강 이 넓어지는 것과 같은 효과로 $\mathrm{F} 1$ 이, 좁아진 외이도 입구가 경구개와 같은 역할을 하여 F2가 높아진 것으로 볼 수 있다.

/ 게/의 실이 음성 포먼트 주파수는 F2가 유의하게 낮아졌다. 전설 중모음 / / / /는 구강 중간에 놓인 혀의 앞쪽 끝이 경구개와 구강을 반쯤 닫은 상태로, 입술은 둥글지 않은 상태로 조음된다. 이 음성은 음장을 지나 다시 좁아진 외이도 입구를 통과하면서 F2가 낮아진 것이다.

/니의 실이 음성은 음장과 비교하여 F1이 유의하게 높아졌다. 후 설 중모음인/시/는 구강 중간에 위치한 혀의 뒤쪽과 연구개가 구강 을 반쯤 닫은 상태로 입술을 둥글게 하고 조음된다. / T/와 마찬가 지로 혀의 높이보다 인두강이 좁아지고 구강이 넓어진 것과 관련 한 변화로 보인다.

실이 음성의 포먼트 주파수는 대체로 중심주파수인 $1,000 \mathrm{~Hz}$ 범 위로 모아지는 경향을 보였다. / / 는 음원으로부터 거리가 멀어지면 서 후설화, 타원형의 외이도 입구가 원순화시켜 F2를 낮춘 것으로 볼 수 있다. / T/는 좁아진 외이도 입구가 협착 되면서 전설화시켜 F2를 높게 한 것으로 보인다. 원순 모음은 입술이나 구강 중간, 인두 강을 좁게 하여 원순화시키거나 성도를 길게 할수록 F3이 낮아진 다. 실이에서 녹음한 원순 모음/T/와/ㄱ/의 F3이 낮아진 것은 이 러한 요인도 공명과 함께 영향을 주었을 것으로 판단된다. 평순 모 음//와///의 F3의 경우는 음원과 거리에 의한 영향이 있었을 것 으로 추정된다. F4는 모든 실험 음성이 음원으로부터의 거리, 외이 도 입구 모양, 외이도 공명 이득 등에 영향을 받은 것으로 판단된다.

음장에서 어음 변별은 포먼트 공간 면적인 음운 공간(phonological space)이 넓어질수록 유리하다(Sher, Shim, \& Ko, 2002). 그러 나 청각기관에서는 서로 다른 매질을 통과하면서 소리를 뇌로 전 달하기 때문에 손실이 발생하고, 이 손실을 보상하기 위하여 증폭 이 일어난다. 외이에서는 공명으로, 중이에서는 공기를 매질로 전달 되는 소리를 이소골 진동과 내이 림프로 전달하기 위한 임피던스 정합(impedance matching)으로 각각 증폭된다. 실제로 이소골 침 
추관절(incudo-malleolar joint)의 피스톤 운동은 음향 자극과 밀 접하게 관련된다(Gerig et al., 2015). 외이도는 직경 $1 \mathrm{~cm}$ 미만, 길이 $3 \mathrm{~cm}$ 정도에 불과하지만 F2, F3, F4를 중심주파수 또는 주변으로 모아주는데(중심화, centralization) (Figure 1), 이렇게 모아지는 주 파수 범위가 임피던스 정합에 가장 적합한 주파수 대역이다. 즉, $\mathrm{F} 2$, F3, F4의 중심화는 외이가 중이로 소리를 전달 과정에서 발생하는 손실을 최소화 하고, 음성을 충분한 강도로 증폭하여 내이로 전달 하는데 기여할 수 있다. 또 F3, F4의 주파수 이동은 성악가들이 성 도 길이를 달리 하여 음악 포먼트 대역인 2,000-3,000 Hz 범위 (Guzman et al., 2013; Hong, Kim, \& Kim, 2006)로 발성하는 것처 럼 청자에게 높은 품질의 음성을 전달하기 위한 외이의 노력으로 볼수 있다.

$\mathrm{F} 1, \mathrm{~F} 2$ 는 남자보다 여자의 / / /, / //, / ㄱ/가 높고 / ㄷ/,/ / / 가 낮다 (Kim et al., 2013). 실이에서 녹음한 음성은 여자의 경우 / / / 의 F1, F2가 낮아졌고, ///의 F2, / T/의 F1, F2가 높아졌다(Heo \& Kang, 2017). 남자 음성을 녹음한 이 연구의 경우 / ㅅ/의 F1, / T/의 F1, F2 가 높아졌고///,/N/의 F2가 낮아졌다. 포먼트 주파수는 조음 거리 가 다른 남녀의 생리학적 특성으로 달라질 수 있고(Oh, 2012), 포먼 트 주파수 표준편차도 차이(Yang, 2008)가 나타날 수 있다. 따라서 실이 음성 특성에 대한 성별 영향에 대한 후속 연구가 필요하다.

결론적으로 실이 음성의 포먼트 주파수는 공명, 음원으로부터 거리 등의 영향으로 주파수가 모아진다. 이러한 변화는 음색 및 개 인 목소리의 특성을 해석하고 어음을 이해하는데 긍정적인 영향을 주기 위한 것으로 판단된다. 이 연구 결과는 다양한 음향분석 지표 를 이용한 후속 연구를 통해 규명할 필요가 있고, 방향성, 청각처 리, 청각적 이해, 보청기나 인공와우 등의 증폭기 사용 과정에서 음 성 언어 이해, 경쟁 잡음 환경과 음원 위치에 따른 언어 이해 등의 연구에 활용될 수 있을 것으로 기대된다.

\section{REFERENCES}

Borden, G. J., Harris, K. S., \& Raphael, L. J. (2000). Speech science primer: physiology, acoustics, and perception of speech (Kim et al., Trans.). Seoul: Hankookmunhwasa.

Choi, A. H., Lee, M. S., Choi, A. R., \& Heo, S. D. (2009). Resonance changes in the external auditory canal associated with the ear canal volume. Phonetics and Speech Sciences, 1, 155-158.

Chung, B. Y., Lim Y. J., Kim, M. J., Nam, S. E., Lee, S. P., \& Kwon, H. B. (2010). The effect of palatal height on the Korean vowels. Journal of the Korean Academy of Prosthodontics, 48, 69-74.
Denes, P. B., \& Pinson, E. N. (1995). The speech chain: the physics and biology of spoken language (D. H. Ko et al., Trans.). Seoul: Hansinmunhwasa.

Ferrand, C. T. (2007). Speech science: an integrated approach to theory and clinical practice (2nd ed., J. Han \& Y. Choi, Trans.) Seoul: SigmaPress.

Gerig, R., Ihrle, S., Röösli, C., Dalbert, A., Dobrev, I., Pfiffner, F., ... \& Sim, J. H. (2015). Contribution of the incudo-malleolar joint to middle-ear sound transmission. Hearing Research, 327, 218-226.

Guzman, M., Laukkanen, A. M., Krupa, P., Horacek, J., Svec, J. G., \& Geneid, A. (2013). Vocal tract and glottal function during and after vocal exercising with resonance tube and straw. Journal of Voice, 27, 523-534.

Heo, S. D. (2012). Pure external auditory canal resonance. Journal of SpeechLanguage \& Hearing Disorders, 21, 465-473.

Heo, S. D., \& Kang, H. R. (2017). Formant frequency change of female voice /a/, /i/, /u/ in real ear. Phonetics and Speech Sciences, 9, 49-53.

Heo, S. D., Lee, J. H., Jeon, S. M., \& Kim, I. A. (2010). Resonance in the concha cavity related with the size of the pinna. Korean Journal of Communication \& Disorders, 15, 107-113.

Heo, S. D., Yoo, J. H., Jung, S. I., \& Lee, M. H. (2016). Change of formant frequencies in real ear. Proceeding of the Korean Academy of Speech-Language Pathology and Audiology, 76-77.

Hong, K. H., Kim, H. K., \& Kim, S. S. (2006). The professional singer's voice evaluation between western singing and Pansori based on vocal fold profiles and acoustic representation. Korean Journal of Communication \& Disorders, 11, 153-164.

Johnson, K. (2003). Acoustic \& auditory phonetics (2nd ed., H. S. Park, Trans.). Seoul: Hanbitmoonhwa.

Kent, R., \& Read, C. (2003). The acoustic analysis of speech. New York, NY: Thompson Learning.

Kim, M., \& Heo, S (2016). Effects of vent diameter on real ear acoustics. Audiology and Speech Research, 12, 204-208.

Kim, S. O., \& Yoon, K. C. (2015). A study on the male vowel formants of the Korean corpus of spontaneous speech. Phonetics and Speech Sciences, 7, 95-102.

Kim, Y. S., Kim, K. H., Kim, J. Y., \& Jang, J. S. (2013). A study on the formant comparison of Korean monophthongs according to age and gender: a survey on patients in oriental hospitals. Phonetics and Speech Sciences, 5, 7380 .

Kwon, M. J., Ko, Y. O., Kim, H. K., Lee, E. J., \& Jeong, O. R. (2007). A study on the pitch and formants of vowels produced by monolingual and bilingual children. Speech Sciences, 14, 47-57. 
Martin, F. N., \& Clark, J. G. (2015). Introduction to audiology (12th ed.). Seoul: Pakhaksa.

Oh, E. J. (2012). Effects of speaker gender on vowel space size and vowel changes in Korean. Journal of Studies in Language, 28, 531-553.

Parise, C., \& Pavani, F. (2011). Evidence of sound symbolism in simple vocalizations. Experimental Brain Research, 214, 373-380.

Sehr, K. H., Shim, H. I., \& Ko, D. H. (2002). Some characteristics of formant frequencies produced by hearing impaired and normal adult male. Journal of Speech \& Hearing Disorders, 11, 239-253.
Yang, B. G. (2008). Formant measurements of complex waves and vowels produced by students. Speech Sciences, 15, 39-52.

Yang, B. G. (2014). Spectral characteristics and formant bandwidths of English vowels by American males with different speaking styles. Phonetics and Speech Sciences, 6, 91-99.

Yi, S. P. (2011). An analysis of formants extracted from emotional speech and acoustical implications for the emotion recognition system and speech recognition system. Phonetics and Speech Sciences, 3, 45-50. 


\section{국문초록}

\section{외이 공명이 남자 음성 포먼트 주파수에 미치는 영향}

허승덕 ${ }^{1}$ 강희라 $\cdot$ 고도흥 ${ }^{3}$

${ }^{1}$ 대구대학교 재활과학대학 언어치료학과, ${ }^{2}$ 대구대학교대학원 재활과학과, ${ }^{3}$ 한림대학교 언어청각학부 언어병리학전공

배경 및 목적: 소리는 음장을 지나 외이도, 중이, 내이 등으로 상행한다. 외이도는 음향에너지 특성이 유지되는 곳으로 공명에 의해 말 소리의 음향학적 특성이 달라질 것으로 예상된다. 이 연구는 실이에서 음성의 포먼트 주파수를 분석하여, 외이 공명이 음성에 어떤 영 향을 미치는지 알아보는데 목적이 있다. 방법: 모음은 사용 빈도가 높은// /, / //, / T/, / / /, / ㄱ/를 사용하였다. 음성은 남자가 발성하여 여자 12 명의 외이도 내부와 이개 상부에서 각각 녹음하였다. 이들 음성은 포먼트 주파수를 분석한(Praat ver. 6.0.19) 후 기술통계 하였 고, 대응표본 $t$-test (SPSS ver. 22.0)와 Wilcoxon test로 검증하였다. 결과: 음장과 실이 음성 사이에서는 / / /의 F3, F4, / / 의 F2, F3, F4, / T/의 모든 포먼트 주파수, / / / 의 F2, F4,/ㄱ/의 F1, F3, F4 등에서 통계적으로 유의한 차이가 관찰되었다( $p<.05)$. 논의 및 결론: 실이 음성의 포먼트 주파수는 공명, 음원으로부터 거리 등의 영향을 받아 주파수가 모아진다. 이러한 변화는 음색 및 개인 목소리의 특성을 해석하고 어음을 이해하는데 긍정적인 영향을 줄 것으로 기대된다.

핵심어: 포먼트 주파수, 공명, 외이도

본 연구는 2016년 대구대학교 연구비 지원을 받아수행된 연구임.

\section{참고문헌}

권미지, 고영옥, 김혜경, 이은정, 정옥란(2007). 이중언어 환경 아동의 모음 포먼트 특성에 관한 연구. 음성과학, 14, 47-57.

김민성, 허승덕(2016). 환기구 직경이 실이 음향에 미치는 영향. 청능재활, 12, 204-208.

김순옥, 윤규철(2015). 한국어 자연발화음성코퍼스의 남성 모음 포먼트 연구. 말소리와음성과학, 7, 95-102.

김영수, 김근호, 김종열, 장준수(2013). 연령 및 성별에 따른 한국인 단모음 포먼트 비교에 관한 연구: 한방병원 내원환자를 중심으로. 말소리와 음성 과학, 5, 73-80.

서경희, 심홍임, 고도흥(2002). 청각장애 남성과 건청 남성이 산출한 단모음의 포먼트 특성. 언어치료연구, 11, 239-253.

양병곤(2008). 복합음과 대학생이 발음한 모음 포먼트 측정. 음성과학, 15, 39-52.

양병곤(2014). 발화방식에 따른 미국인 남성 영어모음의 스펙트럼 특성과 포먼트 대역. 말소리와음성과학, 6, 91-99.

오은진(2012). 모음 공간의 크기 및 모음 변화에 대한 화자성별의 효과-한국어의 경우. 언어연구, 28, 531-553.

이서배(2011). 독일어 감정음성에서 추출한 포먼트의 분석 및 감정인식 시스템과 음성인식 시스템에 대한 음향적 의미. 말소리와 음성과학, 3, 45-50. 정보윤, 임영준, 김명주, 남신은, 이승표, 권호범(2010). 구개의 높이가 한국어 모음 발음에 미치는 효과에 관한 연구. 대한치과보철학회지, 48, 69-74. 최아현, 이미소, 최아름, 허승덕(2009). 외이도용적에 따른 외이도 공명의 변화. 말소리와 음성과학, 1, 155-158.

허승덕 (2012). 순수 외이도 공명. 언어치료연구, 21, 465-473.

허승덕, 강희라(2017). 실이에서 여자 음성 / / /,///,/T/의 포먼트 주파수 변화. 말소리와 음성과학, 9, 49-53.

허승덕, 유재형, 정세인, 이민희(2016). 실이에서 음영대주파수 변화. 한국언어청각임상학회 학술대회 발표논문집, 76-77.

허승덕, 이제현, 전성민, 김인아(2010). 이개 크기에 따른 이개강 공명. 언어청각장애연구, 15, 107-113.

홍기환, 김현기, 김선숙(2006). 판소리 가수와 전문 성각가의 발성 평가를 위한 성문의 특성 및 음향학적 분석. 언어청각장애연구, 11, 153-164.

Carole T. Ferrand (2007). 언어임상을 위한음성과학(한지연, 최양규 역). 서울: 시그마프레스.

Gloria J. Borden, Katherine S. Harris, Lawrence J. Raphael (2000). 음성과학: 조음, 음향, 청각음성학(김기호, 양병곤, 고도흥, 구희산 역). 서울: 한국문화사. Frederick N. Martin, John Greer Clark (2015). 청각학개론 12판(허승덕 역). 서울: 박학사.

Keith Johnson (2003). 음향 및 청취 음성학의 이해 2판(박한상 역). 서울: 한빛문화.

Peter B. Denes, Elliot N. Pinson (1995). 음성언어의 이해(고도흥, 구기산, 김기호, 양병곤 역). 서울: 한신문화사. 